\title{
WHAT MAKES A VECTOR A VECTOR, AND WHY IS THAT IMPORTANT?
}

\author{
MICHAEL J. TURELL \\ VectorID LLC, Frederick, MD 21702 \\ mturell@erols.com
}

Subject Editor: Rui-De Xue

\begin{abstract}
Mosquitoes and other arthropods can transmit pathogens that currently cause millions of cases of illness and over 700,000 deaths annually. For most of these, the most efficient prevention is mosquito (or vector) control. However, only a small number of mosquito species are responsible for pathogen transmission, and different species are important for different pathogens. Because mosquito (vector) control tends to be focused on specific species, it is critical to ensure that the control efforts are directed at the species that are actually involved in pathogen transmission in the real world. Therefore, it is important to understand what makes a vector a vector and the various factors that affect the ability of a potential "vector" to actually transmit a pathogen.
\end{abstract}

Key Words: Vector, Virus, Control, Disease, Mosquito

Malaria, dengue, Zika, chikungunya, yellow fever, tick-borne encephalitis, and Lyme disease are but a few of the diseases caused by pathogens transmitted by mosquitoes and other arthropods. These pathogens cause millions of cases of disease and over 700,000 deaths each year (World Health Organization 2021). Unfortunately, licensed vaccines are not available for most of these diseases, and the only method of preventing them is to reduce, or hopefully eliminate, the vector population. Mosquito Control Departments (or Mosquito Control Districts) or their equivalents have been established all over the world in an attempt to not only reduce pest mosquitoes, but more importantly, to reduce the risk of transmission of pathogens causing disease in humans and domestic animals. From here on, I may only use "mosquito" to represent all potential vectors, but the reader should remember that what I am saying also applies to sand flies, ticks, and other potential vectors.

Unfortunately, there is no simple procedure that kills all mosquitoes. Like with a vaccine, each type of control is generally directed at some specific species or group of species of mosquitoes. Some controls are directed at larvae, while others are directed at the adults. The controls are applied to different habitats and at different times of day, depending on which mosquito is the target for that particular control. Some mosquitoes are diurnal and are only active during the day. Therefore, spraying at night would have very little effect on them. Others are nocturnal and are only active at night, so spraying during the day would have very little effect on them. While still others are primarily crepuscular and are primarily active at dusk or dawn, so spraying during bright sun or late at night may have little effect on these species. Therefore, depending on the target of the control, pesticide application would be applied at different times of day. Some methods are species specific. For example. release of sterile male Ae. aegypti may be helpful controlling future outbreaks of Zika, dengue, or chikungunya, but would be worthless for preventing West Nile. Similarly, larval habitats differ by mosquito species. For example, the procedures used to control larval Aedes taeniorhynchus (Wiedemann) may have little or no impact on Culex quinquefasciatus Say, despite the fact that Altosid ${ }^{\circledR}$ was effective against both species (Floore et al. 1991). Similarly, adult spraying may be more efficient at controlling Aedes vexans (Meigen) 
than Culex tarsalis Coquillett, even when they are co-located as adults (Gujral et al. 2007). Therefore, the control procedure needs to be directed at the species that needs to be controlled, not at "mosquitoes" in general.

Despite there being $>3,500$ different kinds of mosquitoes (Harbach 2013), only a relatively few are pests of humans, and only a very few are involved in pathogen transmission. Even more importantly, the mosquitoes that transmit one pathogen may not be able to transmit other pathogens. For example, the primary vectors of malaria, West Nile virus (WNV), and Zika virus (ZIKV) are completely different, and the important vectors of any of these are essentially unable to transmit either of the other two pathogens. Various Anopheles species are the primary vectors of human malaria, while various Culex species (primarily, Culex nigripalpis (Theobald), Culex pipiens (L), Cx. quinquefasciatus, and Cx. tarsalis) (Goddard et al. 2002; Andreadis 2012) are the principal vectors of $\mathrm{WNV}$ in the U.S. In contrast, essentially only Aedes aegypti (L.) is important as a vector of ZIKV. Although numerous species of mosquito in addition to Ae. aegypti have been shown in the laboratory to be competent vectors of ZIKV (Azar et al. 2017; Ciota et al. 2017; Dibernardo et al. 2017; O'Donnell et al. 2017), these other species are unlikely to be involved in transmitting ZIKV in the real world. Because in most parts of the world ZIKV is an anthroponotic virus, only humans can serve as a source of this virus for mosquitoes. Therefore, in order to transmit ZIKV, the same individual mosquito needs to feed on a viremic person to pick up the virus, and then needs to feed on a second human sometime later to transmit the virus. While many species readily feed on humans, very few preferentially feed on humans and thus it would be extremely unlikely for a single individual mosquito to take two separate blood meals on a human. That is why, despite there being $>5,000$ reported imported cases of Zika infection in the U.S., with $>1,000$ occurring in areas where Aedes albopictus (Skuse) is one of the primary pest mosquitoes (CDC 2021), no locally transmitted cases were detected in any area where $A e$. aegypti were not a known pest.
Because bites from non-vector mosquitoes raise people's awareness about mosquitoes and the need to take precautions, merely controlling "mosquitoes" may actually have detrimental effects concerning disease suppression. As WNV spread across the U.S. in 2003, a study found that in two areas with similar demographics, more intensive mosquito control was inversely related to the amount of West Nile disease detected (Gujral et al. 2007). This unanticipated effect was probably due to intensive control of Ae. vexans, a severely painful and annoying mosquito that does not transmit WNV in the real world, but only limited control of $C x$. tarsalis, the most important vector species in the area (Goddard et al. 2002; Turell et al. 2002). There were a lot of television, radio, and newspaper warnings at the time to avoid mosquitoes, apply repellants, and to protect yourself from mosquito bites to reduce your risk of becoming infected with this new virus. However, in areas with normal mosquito control, there were still sufficient Ae. vexans biting so that people were concerned and used various methods to reduce mosquito biting, e.g., applied repellants and wore clothing that protected skin from mosquito bites. This reduced the number of bites from $C x$. tarsalis, and therefore the amount of transmission of WNV. However, in areas with the more intensive control, Ae. vexans populations were greatly reduced. The people living there had minimal detectable mosquito bites and were thus not as concerned about the need to protect themselves from mosquitoes. Because of this, there were many more bites from $C x$. tarsalis, and thus many more cases of disease caused by WNV.

So, what makes a vector a vector, or more importantly, what makes a vector an important vector in a particular area? The mere isolation of a virus from a mosquito does not mean that the species is a vector of that virus. If the mosquito had recently fed on a viremic host, the mosquito would contain both infectious virus as well as viral RNA, even if that species was unable to become infected with or to transmit that virus. That is why mosquito species need to be tested to determine if they are competent vectors of 
a particular pathogen. Obviously, if the species is not a competent vector, i.e., is unable to become infected or to transmit virus after oral exposure to the virus, then that species is not likely to be an important vector. However, different geographic populations of a mosquito species can differ significantly in their vector competence for a particular virus. For example, Ae. vexans from the southeastern U.S. are moderately efficient vectors of Rift Valley fever virus (RVFV) (Turell et al. 2013), while those from the northwestern U.S. or southern Canada are virtually incompetent (Turell et al. 2010, Iranpour et al. 2011). Because Ae. vexans readily feeds on large mammals, it might be an important vector in the southeastern U.S., but would be much less important in the northwestern U.S. There are numerous other examples where geographic populations differ greatly in their vector competence for a variety of viruses including chikungunya virus (CHIKV) and Ae. albopictus (Tesh et al. 1976), dengue virus (DENV) and $A e$. aegypti (Ye et al. 2014), and western equine encephalitis virus and $C x$. tarsalis (Hardy et al. 1976). Therefore, not only is the vector competence of a potential vector species important, but the competence of the local population of that species is important. However, just because a particular species is competent in the laboratory may not be sufficient. For nearly all outbreaks of chikungunya, Ae. aegypti has been the most important vector. Although the A226V amino acid substitution in the E1 envelope glycoprotein that enhances the ability of Ae. albopictus to transmit CHIKV has been cited as the reason for the 2005-2007 outbreaks of chikungunya that were driven by Ae. albopictus (Tsetsarkin et al. 2007, Riccardo et al. 2019), this mutation developed well into the outbreak. It is more likely that an outbreak involving $A e$. albopictus selected for a strain of virus even more efficiently transmitted by this species than that the mutation allowed Ae. albopictus to serve as the vector. It is possible that in areas where Ae. albopictus has served as a significant vector, other possible blood sources, particularly dogs, may not have been present in sufficient numbers to inhibit feeding on humans. A previous study showed that Ae. albopictus was already a highly competent vector of CHIKV, even without the A226V mutation. When numerous geographic populations of both Ae. aegypti and Ae. albopictus were allowed to feed concurrently on the same viremic monkey, every one of the 10 geographic strains of Ae. albopictus was more susceptible than any of the seven strains of Ae. aegypti (Turell et al. 1992). Why then is Ae. aegypti, which in the laboratory is a less efficient transmitter of CHIKV than Ae. albopictus, normally a more important vector of CHIKV? Remember, CHIKV is an anthroponotic pathogen, and as such, the vector needs to feed twice on a human in order to be able to transmit CHIKV. It is well known that most populations of Ae. aegypti preferentially feed on humans (Scott et al. 1993), but Ae. albopictus tend to be more opportunistic feeders (Richards et al. 2006). In addition, while most mosquito species tend to obtain nourishment from nectar after a blood meal, Ae. aegypti tend to take multiple blood meals on humans during each gonotrophic cycle, thus greatly increasing its contact with humans and its ability to become infected and then transmit an anthroponotic virus (Scott et al. 1997; Costero et al. 1998). Taking of multiple blood meals per gonotrophic cycle further enhances vector competence as the stretching of the midgut due to ingestion of blood appears to enhance the development of a disseminated infection (Armstrong et al. 2020).

For most arboviruses, feeding preference of the potential vector is critical. Mosquitoes that preferentially feed on birds would be very poor vectors of CHIKV, DENV, or RVFV, as these are all viruses that affect and replicate in mammals. Similarly, mosquitoes that preferentially feed on mammals would be poor maintenance vectors of $\mathrm{WNV}$, eastern equine encephalitis virus or western equine encephalitis virus as even though these viruses produce disease in various mammals, they do not produce a sufficient viremia in mammals to infect a mosquito. However, mosquitoes that feed on both mammals and birds are dangerous as they can serve as a bridge vector, picking the virus up from an 
infected bird and transmitting it to a susceptible mammal. Even if a particular species is highly competent and feeds on the appropriate host, if it is present in low numbers, then it would not likely be important. To be important, the potential vector needs to be competent, feed on the appropriate vertebrate hosts, and occur in sufficiently high numbers to serve as a vector.

When controlling mosquitoes or other vectors for disease suppression, it is important to know what the potential vectors are in the area. Which species have been shown to be able to transmit the pathogen? Which species feed on the appropriate host? Which species are occurring (or are predicted to occur by environmental predictors, e.g., tides, rainfall, etc.) in sufficient numbers to be a problem? Once these potential vectors have been identified, they should be prioritized for control based on how likely they are to play a role in pathogen transmission. Remember, killing the wrong mosquito may actually make the disease situation worse.

\section{REFERENCES}

Andreadis TG. 2012. The contribution of Culex pipiens complex mosquitoes to transmission and persistence of West Nile virus in North America. J Am Mosq Control Assoc 28(4 Suppl):137-151.

Armstrong PM, Ehrlich HY, Magalhaes T, Miller MR, Conway PJ, Bransfield A, Misencik MJ, Gloria-Soria A, Warren JL, Andreadis TG, Shepard JJ, Foy BD, Pitzer VE, Brackney DE. 2020. Successive blood meals enhance virus dissemination within mosquitoes and increase transmission potential. Nat Microbiol 5(2):239-247.

Azar SR, Roundy CM, Rossi SL, Huang JH, Leal G, Yun R, Fernandez-Salas I, Vitek CJ, Paploski IAD, Stark PM, Vela J, Debboun M, Reyna M, Kitron U, Ribeiro GS, Hanley KA, Vasilakis N, Weaver SC. 2017. Differential vector competency of Aedes albopictus populations from the Americas for Zika virus. Am J Trop Med Hyg 97 (2):330-339.

Centers for Disease Control and Prevention. 2021. Zika virus. https://www.cdc.gov/zika/reporting/index. html. Accessed on 4 February 2021

Ciota AT, Bialosuknia SM, Zink SD, Brecher M, Ehrbar DJ, Morrissette MN, Kramer LD. 2017. Effects of Zika virus strain and Aedes mosquito species on vector competence. Emerg Infect Dis 23(7):11101117.

Costero A, Edman JD, Clark GG, Scott TW. 1998. Life table study of Aedes aegypti (Diptera: Culicidae) in Puerto Rico fed only human blood versus blood plus sugar. J Med Entomol 35(5):809-813.

Dibernardo A, Turell MJ, Lindsay LR, Loomer C, Iranpour M. 2017. Vector competence of some mosquito species from Canada for Zika virus. JAm Mosq Control Assoc 33(4):276-281.

Floore TG, Rathburn CB Jr, Dukes JC, Clements BW Jr, Boike AH Jr. 1991. Control of Aedes taeniorhynchus and Culex quinquefasciatus emergence with sustained release Altosid sand granules and pellets in saltwater and freshwater test plots. J Am Mosq Control Assoc 7:405-408.

Goddard LB, Roth AE, Reisen WK, Scott TW. 2002. Vector competence of California mosquitoes for West Nile virus. Emerg Infect Dis 8(12):1385-1391.

Gujral IB, Zielinski-Gutierrez EC, LeBailly A, Nasci R. 2007. Behavioral risks for West Nile virus disease, northern Colorado, 2003 Emerg Infect Dis 13(3):419-425.

Harbach, R.E. 2013. Mosquito Taxonomic Inventory. http://mosquito-taxonomic-inventory.info/ [accessed 6 February 2021]

Hardy JL, Reeves WC, Sjogren RD. 1976. Variations in the susceptibility of field and laboratory populations of Culex tarsalis to experimental infection with western equine encephalomyelitis virus. Am J Epidemiol 103(5):498-505.

Iranpour M, Turell MJ, Lindsay LR. 2011. Potential for Canadian mosquitoes to transmit Rift Valley fever virus. J Am Mosq Control Assoc 27 (4):363-369.

O'Donnell KL, Bixby MA, Morin KJ, Bradley DS, Vaughan JA. 2017. Potential of a northern population of Aedes vexans (Diptera: Culicidae) to transmit Zika virus. J Med Entomol 54(5):1354-1359.

Riccardo F, Venturi G, Di Luca M, Del Manso M, Severini F, Andrianou X, Fortuna C, Remoli ME, Benedetti E, Caporali MG, Fratto F, Mignuoli AD, Rizzo L, De Vito G, De Giorgio V, Surace L, Vairo F, Angelini P, Re MC, Amendola A, Fiorentini C, Marsili G, Toma L, Boccolini D, Romi R, Pezzotti P, Rezza G, Rizzo C. 2019. Secondary autochthonous outbreak of chikungunya, southern Italy, 2017. Emerg Infect Dis 25(11):2093-2095.

Richards SL, Ponnusamy L, Unnasch TR, Hassan HK, Apperson CS. 2006. Host-feeding patterns of Aedes albopictus (Diptera: Culicidae) in relation to availability of human and domestic animals in suburban landscapes of central North Carolina. J Med Entomol 43(3):543-551.

Scott TW, Chow E, Strickman D, Kittayapong P, Wirtz RA, Lorenz LH, Edman JD. 1993. Blood-feeding patterns of Aedes aegypti (Diptera: Culicidae) collected in a rural Thai village. J Med Entomol 30 (5):922-927.

Scott TW, Naksathit A, Day JF, Kittayapong P, Edman JD. 1997. A fitness advantage for Aedes aegypti and the viruses it transmits when females feed only on human blood. Am J Trop Med Hyg 57 (2):235-239.

Tesh RB, Gubler DJ, Rosen L. 1976. Variation among geographic strains of Aedes albopictus in susceptibility to infection with chikungunya virus. Am J Trop Med Hyg 25 (2):326-335.

Tsetsarkin KA, Vanlandingham DL, McGee CE, Higgs S. 2007. A single mutation in chikungunya virus affects vector specificity and epidemic potential. PLoS Pathog 3(12):e201.

Turell MJ, O'Guinn ML, Dohm DJ, Webb JP Jr, Sardelis MR. 2002. Vector competence of Culex tarsalis from Orange County, California, for West Nile virus. Vector Borne Zoonotic Dis 2(3):193-196.

Turell MJ, Beaman JR, Tammariello RF. 1992. Susceptibility of selected strains of Aedes aegypti and Aedes albopictus (Diptera: Culicidae) to chikungunya virus. J Med Entomol 29(1):49-53. 
Turell MJ, Britch SC, Aldridge RL, Kline DL, Boohene C, Linthicum KJ. 2013. Potential for mosquitoes (Diptera: Culicidae) from Florida to transmit Rift Valley fever virus. J Med Entomol 50(5):1111-1117.

Turell MJ, Wilson WC, Bennett KE. 2010. Potential for North American mosquitoes (Diptera: Culicidae) to transmit Rift Valley fever virus. J Med Entomol 47(5):884-889.
World Health Organization. 2021. Vector-borne diseases. https://www.who.int/news-room/fact-sheets/ detail/vector-borne-diseases, [accessed 6 February 2021].

Ye YH, Ng TS, Frentiu FD, Walker T, van den Hurk AF, O’Neill SL, Beebe NW, McGraw EA. 2014. Comparative susceptibility of mosquito populations in North Queensland, Australia to oral infection with dengue virus. Am J Trop Med Hyg 90(3):422-430. 